\title{
Developing Long Term Student and Faculty Exchanges with a German University: Challenges and Successes
}

\author{
By \\ Wendy R. Stary \\ University of Wisconsin-Stout \\ Department of Engineering and Technology \\ Menomonie, Wisconsin 54751 \\ E-mail: staryw@uwstout.edu \\ 715-829-7121 \\ John R. Schultz \\ Program Director, Engineering Technology \\ University of Wisconsin-Stout \\ Department of Engineering and Technology \\ Menomonie, Wisconsin 54751 \\ E-mail: schultzj@uwstout.edu \\ 715-232-2348
}

\begin{abstract}
Though vast in overall size, the world today seems quite small due to the ease with which people travel from one region to the next. In business and industry it is quite common for companies to have facilities, or at least customers, world-wide. This often requires employees of these companies to travel and communicate with people of diverse cultures on a regular basis. In order to better prepare the future workforce for success in this environment, the faculty and staff at the University of Wisconsin-Stout endeavor to create opportunities that allow their students to study abroad under many different contexts. Specific to this paper a joint venture between the UWStout and the University of Applied Science, Darmstadt, Germany, Plastics Engineering programs, that began in October, 2010, will be discussed. The paper will focus on the desired goals and objectives for both students and faculty involved in the initiative, the many challenges involved in carrying out specific types of exchanges, outcomes from the activities carried out thus far, and a summary of proposed next steps for further development of the exchange program.
\end{abstract}

\section{Introduction}

Providing international and intercultural experiences that improve the communication skills and global perspectives of students is vital to the on-going success and prosperity of today's global economy ${ }^{1}$. Thus, much is being done in higher education to create opportunities for students to study abroad. It is also noteworthy that the increased number of courses offered in English around the world has opened the door to many new programs for students and faculty alike ${ }^{2}$.

Specific to this paper, the international exchange program discussed began with a chance encounter of faculty from the University of Wisconsin-Stout (UW-Stout herein,) and the University of Applied Sciences-Darmstadt, Germany, (h_da herein,) at the K-Show in Dusseldorf, Germany, in October of 2010. It was determined that both universities offered plastics engineering programs with a similar focus on applied learning and research and that it would be beneficial to students from both programs to be able to take classes at either institution. 


\section{Goals and Objectives}

The primary goal of the still-developing exchange program between the UW-Stout and the h_da is to provide continuous opportunities for students from either institution to easily travel and attend courses offered by the other institution. A secondary goal is to create a faculty exchange program involving both teaching and collaborative research opportunities. In order to accomplish these goals several objectives have been completed and still others are in the works. These include the development of faculty-led student exchanges, semester / yearlong student exchanges, collaborative research projects for both students and faculty and faculty exchanges. The final goal is to incorporate all of the above into a formal agreement between the two institutions creating the necessary framework through which on-going endeavors can be carried out seamlessly.

It was desirable to develop opportunities for short-term interactions that did not require students to miss an entire semester at their home institution. The first of these was a faculty-led student exchange to bring students from the UW-Stout to the h-da for a blocked course. A faculty member from UW-Stout co-taught the course in Darmstadt and another faculty member was in charge of the students. This first endeavor brought together faculty from both institutions to meet face-to-face and discuss the logistics of continuing such endeavors and to gain valuable feedback from the students in order to improve the program offerings moving forward.

The next step was to make it easy for students to study abroad at most any point in their academic career. This involved extensive review of the courses offered in the respective programs at both institutions and the creation of a matrix of courses showing which courses could substitute for each other and precisely when these courses would be offered. During the process of creating such a matrix it was also decided that research projects were always a good means of enhancing the overall student experience and would be handled on a case-by-case basis.

Finally, a long-term goal of the collaboration between the UW-Stout and the $\mathrm{h}$ da is a true faculty exchange program. Ideally this would involve faculty from both institutions spending time teaching and conducting research at the other institution.

Carrying out these objectives has, and will continue to involve many key players at both the UW-Stout and the h_da campuses. Much success has already been realized to date thanks to their help, still, many challenges have had to be overcome in the process.

\section{Challenges and Outcomes to Date}

As mentioned previously, the spark for developing an international exchange in Plastics Engineering was the product of conversations at the K-Show in Germany in the fall of 2010. After a great deal of discussion spanning from October 2010 to May 2011, it was decided that a short-term, blocked course might be the best "first step" towards development of an exchange program. Two challenges of taking this step were to determine the appropriate timing of such a course and what course would be offered. Timing was, and continues to be a challenge because the UW-Stout semesters run September - mid-December, and late January - mid-May. The 
h_da semesters are from October - early February, and late March - early July. It was decided that the course would be conducted in January of 2012, in order to overlap with the semester at the $\mathrm{h}$ _da while falling in between semesters at the UW-Stout. For this first offering it was decided that an introductory injection molding course would be used because it was already planned to be taught during the winter semester at the $\mathrm{h}$-da and the curriculum used for that course closely resembled that used for a similar course (MFGT-341) at the UW-Stout for not only Plastics Engineering, but also students in the Engineering Technology Plastics Concentration and Packaging programs. This was important because it added significant numbers to the pool of potential recruits for filling the faculty-led program; such programs require a minimum of 10 students to go forward. The only problem was that the current lecture materials were all in German and the course would be taught in English. It was a somewhat tedious task considering the faculty member from the UW-Stout did not speak German, yet, she and a professor from the $\mathrm{h}$ _da translated the lecture slides in preparation for the first course offering.

The official documentation process to add the study abroad course to the UW-Stout system commenced in June, 2011. The UW Stout has a long history of international education where the Office of International Education (OIE) facilitates international education for Stout students, recruits and assists international students, and assists instructors in developing international experiences. The expression "no job is finished until the paperwork is completed" is applicable to international study. All required forms as well as detailed instructions for developing an international course were available on the UW-Stout OIE website, and the OIE staff was also very knowledgeable and willing to assist with any problems that came up. However, the challenge was getting all of the right information onto the plethora of forms when there were so many key players. In particular, two faculty members (one from each institution) were developing and teaching the course, one faculty member was leading the student exchange from the UW-Stout, and representatives from the OIE at both the UW-Stout and the h_da campuses were lining up the logistics of housing, transportation, language courses and cultural excursions.

Despite a high level of interest expressed by students when the program was first introduced, recruitment proved to be quite difficult and time consuming. MFGT 341 had been offered on the UW-Stout campus every semester for several years. Because of this, many of the Plastics Engineering and Engineering Technology students had already completed the requirement. Others students wanted to go but couldn't justify the extra cost involved for food, transportation, and housing. Thus, only five students were actually enrolled by early October. A "Plan B" was needed to get the course, and exchange program, off the ground.

Arrangements were made with the Packaging and Engineering Technology Program Directors to allow MFGT 341 in Darmstadt as a substitute for another course, MFGT 251 Plastics Materials and Processes. MFGT 251 is one of a three course materials series required by both degrees. Normally MFGT 251 is a prerequisite for MFGT 341. Because non-plastics concentration Engineering Technology and Packaging graduates who work in the plastics industry have a 
greater chance of working in injection molding, and because it was critical in getting the first class on the books, the Program Directors felt this substitution was acceptable. Another option was added that allowed the course to be used as an elective in all Engineering Technology concentrations.

These options were presented to students at the October Advisement Day presentations and slowly, very slowly, with a lot of promotion, students began to enroll. By the end of the fall 2011 semester ten students were registered, had paid their tuition, applied for passports, attended the required international education meetings, and met all the requirements to participate. These included four Plastics Engineering students and six Engineering Technology students. Interestingly, the Engineering Technology students had facilities, industrial, and mechanical design concentrations. Not one Engineering Technology student had a plastics concentration.

The course lectures were blocked into five days spanning a total period of ten days. The other days included time for language and cultural instruction, cultural excursions, and company tours. The itinerary was modeled after a similar exchange program in Darmstadt through UWPlatteville the previous summer. There were two major differences: the UW-Stout course was one week shorter and in January. Because of this less cultural excursions were included and they were all close to Darmstadt. The students' desire to include more cultural experiences led to inconsistent attendance during course lectures. Additionally, the h_da semester was nearly over when MFGT 341 was conducted. This led to fewer of the German students attending lectures regularly or participating in social activities with the UW-Stout students, as they were spending their time preparing for exams.

Evaluation for the course was primarily designed to mimic the normal practice used in Germany where the entire grade is often based on the final exam. However, it was decided that a lab component must be part of the grading criteria. Support for this action was twofold. First, the course is a pre-requisite to an advanced injection molding course for students in the UW-Stout Plastics Engineering program. Second, applied learning through laboratory experiences is the standard practice at the UW-Stout. Thus, two laboratory experiences were incorporated that reinforced the concepts taught during lecture. It is important to note that these laboratory activities were conducted after students returned to the UW-Stout campus. (Final exams were also administered separately for the German and the UW-Stout students.) The UW-Stout students were supplied with a study guide and access to all lecture materials presented at the h_da, such that they could adequately prepare for the final exam. The exam was created to very closely resemble that given to students who take the MFGT-341 course at the UW-Stout campus. Approximately one month after their return to the United States the exam was administered and resulted in a $100 \%$ pass rate.

During the last class session at the $\mathrm{h}$ _da time was set aside for a verbal critique of the program by the students from both institutions. Both the h_da and UW-Stout students expressed a desire to spend more time with each other, particularly requesting more opportunities for social 
interactions. They also requested that the lectures be spread out over more days stating it was difficult to remain focused for that many hours in a row with only short breaks. This was especially true for the German students who, despite being taught the English language since the third grade were not entirely comfortable with using the language for the technical content of the course.

Beyond the challenges related to the actual course, a few others were noted. These were primarily related to striking a balance between allowing the students, all considered legal adults, to be responsible for their own actions while maintaining solid communication with their faculty mentor. Another involved a serious health issue that arose halfway through the trip for one of the students. He had packed prescription medications in anticipation of needing them, but had no idea how much might actually be necessary. The medication ran out and three trips to the hospital were required to get him through the rest of the stay. Fortunately a graduate student from the $\mathrm{h}$-da was provided as a guide and interpreter throughout the trip and she was able to handle the hospital logistics and communications issues. A doctor's approval was needed for the flight back to the US and was secured two days before departure. The final challenge of the trip involved a three hour delay of the return flight from Frankfurt which in turn caused a missed connection in Chicago. This was mostly an inconvenience; however, it did create some concerns over how to handle situations where the group may have to be split up during travel.

The experiences gained from the first trip were used with the intention to improve the international experience for plastics students during the second faculty-led student exchange that was planned for June 2013. This exchange was planned utilizing the same injection molding course only it was blocked over three weeks with lectures on Monday and Tuesday mornings. This time laboratory experiments were also incorporated into those same days in the afternoons. Based on feedback from the students from the first course this arrangement left more time for students to engage in social activities and cultural excursions. The timing also meant better weather in Darmstadt, opening up opportunities for more destinations to be open. Unfortunately, this combination of timing and duration also meant greater expense. While numerous students expressed interest in attending the program, in the end no one completed the application process. There was still interest on the part of the faculty member teaching the course at the $\mathrm{h}$-da campus to have a faculty member from the UW-Stout help teach the course. Thus, a faculty member from the UW-Stout still traveled to Darmstadt to participate in the teaching of the scheduled course.

To date there have not yet been any faculty-led exchanges of students coming from the $h$ da to the UW-Stout. However, one student from the $\mathrm{h}$-da plastics program has completed a full semester of study at the UW-Stout. Part of the challenge to getting more students to come to the UW-Stout is related to the fact that tuition in Germany is subsidized by the government. Students there pay very small fees towards food and transportation as compared to the tuition paid by students in the United States. A long term solution needs to be worked out to create an 
agreement around a formal student exchange that eliminates the tuition burden for the German students in order to recruit more significant numbers of students to come to the UW-Stout.

\section{Next Steps}

In the future faculty members from both the UW-Stout and the $\mathrm{h}$-da plastics programs are interested in completing a formal exchange agreement. It is intended that this agreement will include the matrix of approved course substitutions as well as a plan for how many students can be exchanged each semester / year in order to minimize the cost burden to any one student. It is also desired that faculty-led student exchanges will continue on a periodic basis to provide opportunities to students who may not wish to miss an entire semester on their home campus. Finally, plans are already in the works to bring faculty from the United States to the $h$ _da campus through professorships to teach and expand the number of courses offered in English. It is likely that one or more faculty members from the UW-Stout will participate in this endeavor.

\section{References}

1. Institute of International Education (2007). Meeting America's global education challenge: Current trends in US study abroad and the impact of strategic diversity initiatives. White papers on expanding capacity and diversity in study abroad. New York: Institute of International Education.

2. Altbach, P. G. (2008). The 'subprime' market and international higher education. International Higher Education, 51(Spring), 2-3. 